Abstract-Harbor seals (Phoca vitulina) are an abundant predator along the west coast of North America, and there is considerable interest in their diet composition, especially in regard to predation on valued fish stocks. Available information on harbor seal diets, primarily derived from scat analysis, suggests that adult salmon (Oncorhynchus spp.), Pacific Herring (Clupea pallasii), and gadids predominate. Because diet assessments based on scat analysis may be biased, we investigated diet composition through quantitative analysis of fatty acid signatures. Blubber samples from 49 harbor seals captured in western North America from haul-outs within the area of the San Juan Islands and southern Strait of Georgia in the Salish Sea were analyzed for fatty acid composition, along with 269 fish and squid specimens representing 27 potential prey classes. Diet estimates varied spatially, demographically, and among individual harbor seals. Findings confirmed the prevalence of previously identified prey species in harbor seal diets, but other species also contributed significantly. In particular, Black (Sebastes melanops) and Yellowtail ( $S$. flavidus) Rockfish were estimated to compose up to $50 \%$ of some individual seal diets. Specialization and high predation rates on Black and Yellowtail Rockfish by a subset of harbor seals may play a role in the population dynamics of these regional rockfish stocks that is greater than previously realized.

Manuscript submitted 31 January 2012. Manuscript accepted 31 October 2012. Fish. Bull. 111:13-26 (2013).

doi:10.7755/FB.111.1.2

The views and opinions expressed or implied in this article are those of the author (or authors) and do not necessarily reflect the position of the National Marine Fisheries Service, NOAA.

\title{
New insights into the diets of harbor seals (Phoca vitulina) in the Salish Sea revealed by analysis of fatty acid signatures
}

\author{
Jeffrey F. Bromaghin (contact author)' \\ Monique M. Lance ${ }^{2}$ \\ Elizabeth W. Elliott ${ }^{3}$ \\ Steven J. Jeffries ${ }^{2}$ \\ Alejandro Acevedo-Gutiérrez ${ }^{4}$ \\ John M. Kennish ${ }^{3}$ \\ Email address for contact author: jbromaghin@usgs.gov \\ U. S. Geological Survey \\ Alaska Science Center \\ 4210 University Drive \\ Anchorage, Alaska 99508 \\ ${ }^{2}$ Washington Department of Fish \& Wildlife \\ Wildlife Research Division \\ 7801 Phillips Road SW \\ Lakewood, Washington 98498 \\ ${ }^{3}$ Department of Chemistry and Applied \\ Sciences, Engineering and \\ Technology (ASET) Laboratory \\ University of Alaska Anchorage \\ 3211 Providence Drive \\ Anchorage, Alaska 99508 \\ ${ }^{4}$ Department of Biology \\ Western Washington University \\ 516 High St. MS 9160 \\ Bellingham, Washington 98225-9160
}

The harbor seal (Phoca vitulina) is the most abundant pinniped species in the protected coastal waters of Washington State and British Columbia, Canada (Jeffries et al., 2003). This species is a generalist piscivorous predator, at or near the apex of marine food webs. Such large and mobile endothermic predators require high caloric intake to support growth, reproduction, and foraging activity (e.g., Williams et al., 2004). Given their abundance and trophic position, harbor seals undoubtedly make up an influential component of their marine ecosystems (Sergio et al., 2006; Heithaus et al., 2008; Schmitz et al., 2010).

Numerous fish stocks of historic commercial importance are depressed or have declined significantly in the Salish Sea of western North America, including Pacific Herring (Clupea pallasii), Chinook Salmon (Oncorhynchus tshawytscha) in Puget Sound, Steelhead Trout (O. mykiss), Pacific Hake (Merluccius productus), Walleye Pollock (Theragra chalcogramma), and many species of rockfish (Sebastes spp.) (Federal Register,
2007). Under the Endangered Species Act, the Puget Sound and Georgia Basin distinct population segments of Yelloweye (S. ruberrimus) and Canary ( $S$. pinniger) Rockfish recently were listed as threatened, and Bocaccio (S. paucispinis) was listed as endangered (Federal Register, 2010). Three additional rockfish speciesBrown Rockfish (S. auriculatus), Copper Rockfish (S. caurinus), and Quillback Rockfish (S. maliger)—now are considered federal species of concern, and the remaining 7 species found in the Salish Sea are listed as species of concern by the State of Washington (M. Lance, personal commun.). Continued declines in fish abundance and the failure of depleted populations to recover have elevated concerns among fishing crews, managers, and conservationists (Musick et al., 2001; Williams et al., 2010).

The concurrence of abundant harbor seals and depressed fish populations has stimulated debate about the degree to which harbor seals may regulate prey abundance (Orr et al., 2004). Numerous factors may have contributed to the declines in fish 
abundance, although overexploitation has likely played a prominent role (e.g., Levin et al., 2006). Predation may have contributed to historic declines or may be inhibiting recovery, because the abundance of Salish Sea pinnipeds has been increasing and is thought to be near carrying capacity (Jeffries et al., 2003). Although pinnipeds have the potential to deplete local fish stocks or hinder management actions that would promote the recovery of depleted stocks (Harwood and Croxall, 1988; Bowen et al., 1993; Fu et al., 2001; Bjørge et al., 2002; Boyd, 2002; MacKenzie et al., 2011), there is no direct evidence to that effect in the Salish Sea. Consequently, an improved understanding of the role of pinniped predation in regulation of prey abundance would enhance our knowledge of marine ecosystem dynamics and potentially inform the effective management of fish stocks.

The diets of harbor seals in this region are thought to be composed primarily of adult salmon (Oncorhynchus spp.), Pacific herring, and gadids (Scheffer and Slipp, 1944; Olesiuk, 1993; Tollit et al., 1997; Browne et al., 2002; Wright et al., 2007; Thomas et al., 2011; Lance et al., 2012). However, seals are considered opportunistic predators that target locally abundant prey and switch between prey species in response to changes in prey abundance-a type-III functional response (Holling, 1959; Middlemas et al., 2006). Such predatory behavior, in combination with local and seasonal diversity in the availability of prey (Stasko et al., 1976; Willson and Womble, 2006; Therriault et al., 2009; Thomas et al., 2011), implies harbor seal diet composition will vary both spatially and temporally, and thus complicate accurate diet assessment.

Prior investigations of harbor seal diets in the $\mathrm{Pa}$ cific Northwest have relied primarily on observational studies, stomach content analyses, and especially scat analyses (Scheffer and Slipp, 1944; Everitt et al., 1981; Brown and Mate, 1983; Olesiuk, 1993; Zamon, 2001; Orr et al., 2004; Wright et al., 2007; Thomas et al., 2011; Lance et al., 2012). Such methods provide important insights into predatory behavior and document the presence of particular prey species in predator diets; however, several well-known factors can limit their utility in quantitative investigations of diet (Phillips and Harvey, 2009; Klare et al., 2011). For example, scat analyses frequently are compromised by unequal probabilities of detecting prey classes, as well as by difficulty in derivation of quantitative estimates of diet composition from frequency-of-occurrence data. In addition, results pertain only to a short period of time, ranging from the last predatory event in observational studies to 1-2 days in scat-based investigations (Harvey, 1989; Cottrell and Trites, 2002; Tollit et al., 2004; Trites and Joy, 2005; Hauser et al., 2008; Phillips and Harvey, 2009).

Quantitative fatty acid signature analysis (QFASA; Iverson et al., 2004) has important advantages over other methods of diet assessment. Perhaps, most important, the method produces statistical estimates of diet composition and measures of precision. The number of fatty acids that can be biosynthesized by animals is limited (Ackman, 1989); therefore, the presence of some compounds can be attributed to diet alone. This fact, in combination with the large number of fatty acid compounds present in adipose tissue, particularly in marine ecosystems, enables QFASA to estimate the contribution of a large number of prey classes to diets, limited primarily by the diversity of fatty acids among prey classes. In addition, although most methods of diet assessment provide information only on recent consumption, sampling of adipose deposits may provide insights into diets over a period of weeks to months (Iverson et al., 2004; Budge et al., 2006). QFASA requires the development of comprehensive data on the fatty acid composition of potential prey, work that may be costly or otherwise difficult. Although predators must be captured and handled, only a small incision is required for sampling and predators can be quickly released. Overall, QFASA presents predators with limited negative consequences and can produce diet composition estimates that largely avoid potential biases characteristic of other methods.

We used QFASA to investigate the diets of harbor seals captured from haul-out sites among the San Juan Islands of Washington State and the southern Gulf Islands of British Columbia; both island groups are within the Salish Sea. Blubber samples were collected from captured harbor seals and representative specimens of known or potential prey species also were collected. Samples from both predators and potential prey were analyzed to determine their fatty acid composition, and diet compositions of sampled harbor seals were estimated with QFASA mixture modeling. The resulting estimates provide new insights into harbor seal predation on depressed fish populations and reveal dietary heterogeneity on spatial, demographic, and individual scales.

\section{Materials and methods}

\section{Study area}

The San Juan Islands and the southern Gulf Islands lie in the transboundary waters of Washington State and British Columbia between the Strait of Georgia, Strait of Juan de Fuca, and Puget Sound (Fig. 1). This area is characterized by hundreds of large and small islands, rocky intertidal reefs, protected bays and estuaries, and rich marine life. Harbor seals use more than 150 haul-out locations in the study area, including intertidal sandbars and numerous small islands and rocky reefs distributed throughout the region. Harbor seals are abundant throughout the Salish Sea (Jeffries et al., 2003). 


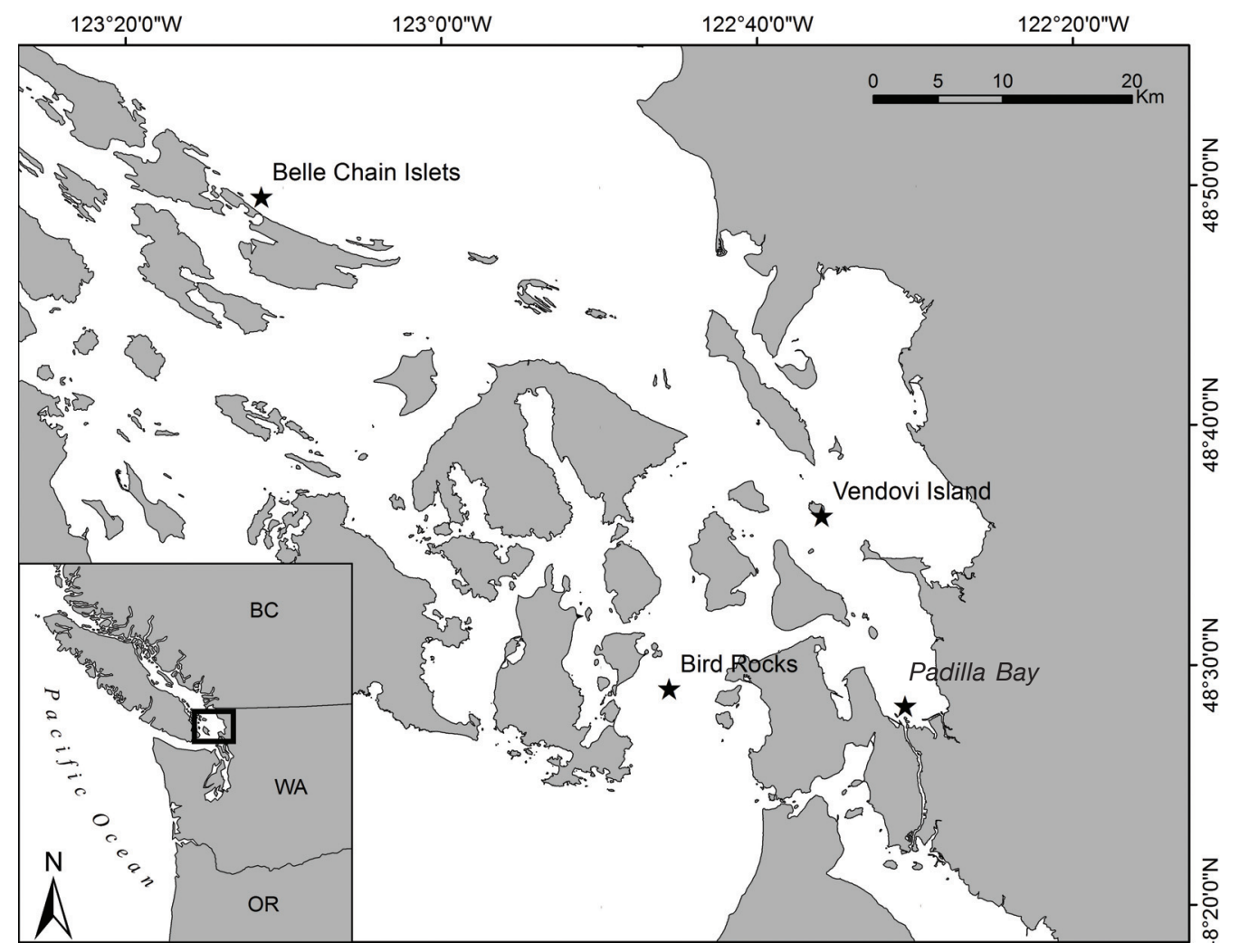

\section{Figure 1}

Map of the San Juan Island region, where samples were collected for our investigation of the diet composition of harbor seals (Phoca vitulina) in the Salish Sea. Harbor seals were captured in the vicinity of Padilla Bay, Bird Rocks, Vendovi Island, and the Belle Chain Islets.

\section{Sampling of predator and prey}

Harbor seals were captured from April 2007 to March 2008 at 3 sites in the San Juan Islands of Washington State and at a fourth site in the adjacent Gulf Islands in British Columbia (Fig. 1). Padilla Bay $\left(48^{\circ} 28.37^{\prime} \mathrm{N}\right.$, $122^{\circ} 30.88^{\prime} \mathrm{W}$ ) is characterized by estuarine-mudflat habitat, Vendovi Island $\left(48^{\circ} 67.10^{\prime} \mathrm{N}, 122^{\circ} 61.10^{\prime} \mathrm{W}\right)$ consists of rocky reef habitat located in close proximity to Bellingham, Samish, and Padilla Bays, and Bird Rocks $\left(48^{\circ} 29.16^{\prime} \mathrm{N}, 122^{\circ} 45.61^{\prime} \mathrm{W}\right)$ comprises rocky reef habitat in Rosario Strait. The fourth site was the Belle Chain Islets, a rocky reef in the southeastern Gulf Islands of British Columbia $\left(48^{\circ} 49.67^{\prime} \mathrm{N}, 123^{\circ} 11.56{ }^{`} \mathrm{~W}\right)$ with habitat similar to that of Bird Rocks.

Forty-nine blubber samples were collected from harbor seals according to standard techniques (Iverson et al., 1997; Walton et al., 2000; Walton and Pomeroy, 2003) under Marine Mammal Protection Act Research Permit 782-1702-00. Seals were captured in salmon landing nets and physically restrained during processing following the method of Jeffries et al. (1993). The sampling location on the left side of the pelvic region was shaved with a razor, rinsed with isopropyl alco- hol, scrubbed with Betadine, and rinsed again with isopropyl alcohol. A complete cross section of blubber from skin to muscle was collected with a sterile, $6-\mathrm{mm}$ biopsy punch. A full cross-section sample provides the most complete information regarding diet because phocid blubber is not homogenous throughout its depth and the inner layer responds most quickly to diet shifts (Iverson et al., 1997). The biopsy site was then filled with antiseptic cream and left open to drain. Each sample was placed immediately in chloroform with $0.01 \%$ butylated hydroxytoluene to inhibit oxidation in glass vials with Teflon lids, placed on ice while in the field, and subsequently stored frozen at $-80^{\circ} \mathrm{C}$ until analysis. Seal samples were associated with these covariates: sampling location, sex, and season (Table 1). Seasons were defined as spring (March to May), fall (October to November), and winter (December to February).

We sampled fish and cephalopod species known to be consumed by harbor seals in the San Juan Islands region on the basis of previous fecal analyses (Lance et al., 2012). Some adult salmon samples were obtained from seafood processors and staff of the NOAA Northwest Fisheries Science Center. Other prey were captured from throughout the study area between June 


\section{Table 1}

Number of harbor seal samples, by location, sex, and season, used in our investigation of diet composition of harbor seals (Phoca vitulina) in the Salish Sea through quantitative fatty acid signature analysis.

\begin{tabular}{lccccccc}
\hline & \multicolumn{3}{c}{ Female } & & \multicolumn{3}{c}{ Male } \\
\cline { 2 - 4 } \cline { 6 - 8 } Location & Spring & Fall & Winter & & Spring & Fall & Winter \\
\hline Belle Chain & 4 & 0 & 0 & & 6 & 0 & 0 \\
Bird Rocks & 1 & 0 & 2 & & 5 & 4 & 2 \\
Padilla Bay & 14 & 1 & 0 & & 3 & 0 & 0 \\
Vendovi Island & 0 & 2 & 1 & & 0 & 4 & 0 \\
& & & & & & &
\end{tabular}

and December, 2008, with a variety of gear, including hook and line, longline, and trawl. Samples were obtained from 269 specimens representing these 20 species: Black (Sebastes melanops), Yellowtail (S. flavidus), Copper, and Puget Sound (S. emphaeus) Rockfish; Chinook, Chum (Oncorhynchus keta), Coho (O. kisutch), Sockeye (O. nerka), and Pink (O. gorbuscha) Salmon; Pacific Herring, Walleye Pollock; Pacific Sand Lance (Ammodytes hexapterus); Northern Anchovy (Engraulis mordax); Shiner Perch (Cymatogaster aggregata); Plainfin Midshipman (Porichthys notatus); Spiny Dogfish (Squalus acanthias); Opalescent Inshore Squid (Loligo opalescens); Kelp Greenling (Hexagrammos decagrammus); Pacific Staghorn Sculpin (Leptocottus armatus); and Starry Flounder (Platichthys stellatus). Specimens were identified with Hart (1973) for fish species and Roper et al. (1984) for squid. Because some species were represented by individuals with differences in size and total fat content (for example, immature and mature species of salmon), 27 prey classes were defined (Table 2).

Prey specimens were placed in airtight plastic bags and stored at $-80^{\circ} \mathrm{C}$ as soon as possible after collection. In the laboratory, each specimen was given a unique sample number, partially thawed, weighed and measured (standard, fork, and total lengths), and homogenized with a medium or large mechanical blender, depending on fish size. The smallest prey animals were homogenized with a mortar and pestle because the blender was ineffective. Stomach contents were not removed from prey specimens, to mimic ingestion by predators (Budge et al., 2002). Approximately 5-10 g of homogenate was placed in labeled scintillation vials with Teflon lids and stored in a $-80^{\circ} \mathrm{C}$ freezer. Samples were express shipped in a cooler on dry ice to the Applied Sciences, Engineering, and Technology (ASET) Laboratory at the University of Alaska Anchorage.

\section{Fatty acid extraction and selection}

All samples were processed at the ASET Laboratory through the use of a method for microscale recovery of total lipids with the Dionex ASE $200^{1}$ automated solvent extraction system (Thermo Fisher Scientific, Waltham, MA), which provides lipids for the determination of 80 unique fatty acids (Dodds et al., 2005). The total body mass, percent fat composition, and fat mass of prey specimens were obtained for 27 prey classes (Table 2). Total mass data were not available for mature Chinook, Sockeye, and Pink Salmon obtained from the Northwest Fisheries Science Center; therefore, an approximate mean mass for these prey classes (e.g., Quinn, 2005) was used in calculation of fat mass. Given the large range of mass among prey classes (Table 2), the results were insensitive to our use of these approximate values.

Extracted lipids were dissolved in hexane to a concentration of $100 \mathrm{mg} / \mathrm{mL}$, hydrolyzed by a base-catalyzed reaction with potassium hydroxide, and then esterified to form fatty acid methyl esters (FAMEs) by reaction with boron trifluoride in methanol. Each sample was spiked with a C21:0 internal standard (25 $\mu \mathrm{g} / \mathrm{mL}$ ) and separated on a Hewlett-Packard 5890 gas chromatograph (GC) with a flame ionization detector (FID) (Hewlett-Packard Co., Palo Alto, California) by using a 60-m J\&W DB-23 column (Agilent Technologies, Inc., Santa Clara, CA) with a $0.25-\mathrm{mm}$ inside diameter and 0.25-um cyanopropyl polysiloxane film. Signal data were collected and analyzed with Agilent GC Chemstation software.

Supelco 37-Component FAME Mix (catalog no. 47885-U; Sigma-Aldrich Co., St. Louis, MI) was used as a continuing calibration verification (CCV) to verify both the retention times and recovery values. This CCV also contained $25 \mu \mathrm{g} / \mathrm{mL}$ of a C21:0 internal standard, which is required to meet a tolerance of no greater than $\pm 20 \%$ of actual value. Analyte identity was verified further by mass spectrometry through the use of a Varian CP3800 GC (Agilent Technologies, Inc.) and a Varian Saturn 2200 ion trap mass spectrometer

\footnotetext{
${ }^{1}$ Mention of trade names or commercial companies is for identification purposes only and does not imply endorsement by the U.S. Government.
} 


\section{Table 2}

The number of prey animals from which fatty acid signature data were obtained $(n)$ and the prey class (class) into which each prey type was assigned after evaluation of discriminant analysis and mean fat mass in our investigation of the diet composition of harbor seals (Phoca vitulina) in the Salish Sea through quantitative fatty acid signature analysis. Prey classes are defined as B\&YR (Black [Sebastes melanops] and Yellowtail [S. flavidus] Rockfish), CR (Copper Rockfish [S. caurinus]), PSR (Puget Sound Rockfish [S. emphaeus]), Chin (mature Chinook Salmon [Oncorhynchus tshawytscha]), Chum (mature Chum Salmon [O. keta]), Coho (mature Coho Salmon [O. kisutch]), Sock (mature Sockeye salmon [O. nerka]), Pink (mature pink salmon [O. gorbuscha]), Sal-M (medium-sized Chinook and Coho Salmon), Sal-S (small Chinook, Chum, Sockeye, and Pink Salmon), Pol (Walleye Pollock [Theragra chalcogramma]), Her (Pacific Herring [Clupea pallasii] at least 2 years old), YH\&SL (Pacific Herring less than 2 years old and Pacific Sand Lance [Ammodytes hexapterus]), NA (Northern Anchovy [Engraulis mordax]), SP (Shiner Perch [Cymatogaster aggregata]), PM (Plainfin Midshipman [Porichthys notatus]), SD (Spiny Dogfish [Squalus acanthias]), OIS (Opalescent Inshore Squid [Loligo opalescens]), G\&S\&F (Kelp Greenling [Hexagrammos decagrammus], Pacific Staghorn Sculpin [Leptocottus armatus], and Starry Flounder [Platichthys stellatus]). For each prey type, the sample size (n), mean (mean), and standard deviation (SD) of total mass, percent fat composition, and total fat mass are shown. Mass data were not available for mature Chinook, Sockeye, or Pink Salmon, and an approximate mean mass was used for the computation of fat mass.

\begin{tabular}{|c|c|c|c|c|c|c|c|c|c|c|c|}
\hline \multirow[b]{2}{*}{ Prey type } & \multirow[b]{2}{*}{$n$} & \multirow[b]{2}{*}{ Class } & \multicolumn{3}{|c|}{ Mass (g) } & \multicolumn{3}{|c|}{ Percent fat } & \multicolumn{3}{|c|}{ Fat mass (g) } \\
\hline & & & $n$ & Mean & SD & $n$ & Mean & SD & $n$ & Mean & SD \\
\hline Black Rockfish & 5 & B\&YR & 5 & 293.8 & 48.3 & 5 & $6.5 \%$ & $0.4 \%$ & 5 & 19.3 & 4.0 \\
\hline Yellowtail Rockfish & 5 & B\&YR & 5 & 152.8 & 28.2 & 5 & $5.7 \%$ & $1.5 \%$ & 5 & 8.8 & 2.6 \\
\hline Copper Rockfish & 12 & $\mathrm{CR}$ & 12 & 201.3 & 195.7 & 12 & $2.4 \%$ & $0.4 \%$ & 12 & 4.7 & 4.5 \\
\hline Puget Sound Rockfish & 14 & PSR & 14 & 53.9 & 8.9 & 5 & $2.2 \%$ & $0.3 \%$ & 5 & 1.1 & 0.4 \\
\hline Chinook, mature & 10 & Chin & 0 & 10000.0 & NA & 10 & $12.2 \%$ & $2.3 \%$ & 10 & 1218.8 & 233.3 \\
\hline Chum, mature & 10 & Chum & 10 & 4955.9 & 784.6 & 10 & $15.1 \%$ & $7.8 \%$ & 10 & 789.7 & 455.6 \\
\hline Coho, mature & 10 & Coho & 10 & 3765.4 & 660.8 & 10 & $5.5 \%$ & $2.8 \%$ & 10 & 208.2 & 125.0 \\
\hline Sockeye, mature & 10 & Sock & 0 & 2500.0 & NA & 10 & $12.4 \%$ & $1.8 \%$ & 10 & 309.4 & 45.4 \\
\hline Pink, mature & 10 & Pink & 0 & 2000.0 & NA & 10 & $5.3 \%$ & $2.1 \%$ & 10 & 105.6 & 43.0 \\
\hline Chinook, medium & 5 & Sal-M & 5 & 133.5 & 70.3 & 5 & $3.0 \%$ & $1.3 \%$ & 5 & 4.8 & 3.1 \\
\hline Coho, medium & 4 & Sal-M & 4 & 193.0 & 28.6 & 4 & $2.9 \%$ & $0.5 \%$ & 4 & 5.7 & 1.7 \\
\hline Chinook, small & 11 & Sal-S & 12 & 20.9 & 8.0 & 12 & $1.3 \%$ & $0.3 \%$ & 12 & 0.3 & 0.2 \\
\hline Chum, small & 12 & Sal-S & 12 & 62.8 & 24.6 & 12 & $2.3 \%$ & $1.1 \%$ & 12 & 1.6 & 1.5 \\
\hline Sockeye, small & 12 & Sal-S & 12 & 15.5 & 2.5 & 12 & $1.5 \%$ & $0.2 \%$ & 12 & 0.2 & 0.1 \\
\hline Pink, small & 12 & Sal-S & 12 & 47.2 & 13.6 & 12 & $2.4 \%$ & $0.8 \%$ & 12 & 1.2 & 0.7 \\
\hline Pollock & 13 & Pol & 13 & 29.4 & 78.6 & 13 & $1.8 \%$ & $0.4 \%$ & 13 & 0.5 & 1.2 \\
\hline Pacific Herring $\geq 2$ yr & 12 & Her & 12 & 37.5 & 4.2 & 12 & $11.7 \%$ & $3.4 \%$ & 12 & 4.4 & 1.6 \\
\hline Pacific Herring $<2$ yr & 12 & YH\&SL & 12 & 5.8 & 0.8 & 12 & $3.5 \%$ & $1.3 \%$ & 12 & 0.2 & 0.1 \\
\hline Pacific Sand Lance & 12 & YH\&SL & 12 & 1.9 & 0.3 & 12 & $3.3 \%$ & $0.8 \%$ & 12 & 0.1 & 0.0 \\
\hline Northern Anchovy & 11 & $\mathrm{NA}$ & 11 & 18.8 & 1.7 & 11 & $12.2 \%$ & $3.4 \%$ & 11 & 2.3 & 0.7 \\
\hline Shiner Perch & 12 & $\mathrm{SP}$ & 12 & 21.0 & 5.8 & 12 & $6.9 \%$ & $2.4 \%$ & 12 & 1.5 & 1.0 \\
\hline Plainfin Midshipman & 9 & $\mathrm{PM}$ & 9 & 61.7 & 13.4 & 9 & $3.4 \%$ & $0.7 \%$ & 9 & 2.1 & 0.6 \\
\hline Spiny Dogfish & 4 & $\mathrm{SD}$ & 4 & 1712.5 & 383.8 & 4 & $9.0 \%$ & $3.6 \%$ & 4 & 160.5 & 83.5 \\
\hline Opalescent Inshore Squid & 12 & OIS & 12 & 7.1 & 1.9 & 12 & $3.0 \%$ & $0.4 \%$ & 12 & 0.2 & 0.1 \\
\hline Kelp Greenling & 7 & G\&S\&F & 7 & 179.7 & 396.3 & 7 & $1.5 \%$ & $0.4 \%$ & 7 & 3.0 & 6.8 \\
\hline Pacific Staghorn Sculpin & 12 & G\&S\&F & 12 & 21.0 & 10.1 & 11 & $1.5 \%$ & $0.6 \%$ & 11 & 3.4 & 5.7 \\
\hline Starry Flounder & 11 & G\&S\&F & 11 & 220.2 & 410.1 & 11 & $1.5 \%$ & $0.6 \%$ & 11 & 3.4 & 5.7 \\
\hline
\end{tabular}

with a scan range of 50-400 mass-to-charge ratios $(\mathrm{m} / \mathrm{z})$. Additionally, a National Institute of Standards and Technology 1946 international standard was used to externally verify the method and the quality of recoveries.

The ASET Laboratory implements several protocols to improve data quality that are not routinely implemented in analyses of fatty acid data. Rather than normalize the peak data of each sample to C18:0, the laboratory adds an internal standard to all samples, method blanks, and CCVs. This protocol is beneficial because it provides a data point of known quantity to each resulting set, including blanks, allowing the significance of low-recovery peak data to be verified. In addition, because normalization to a recovered compound incorrectly entails the assumption that all compounds respond equally in the FID, use of an internal standard avoids errors that might otherwise result from that assumption (Dodds et al., 2005). The laboratory also verifies the identity of each peak by using a GC mass spectrometer (GC-MS)-verification that is necessary to eliminate misclassification of non-fatty acid 
byproducts from the derivatization process. Finally, the laboratory performs periodic standard calibrations of the spectrometer at varying levels of concentration to determine the limit-of-detection for each compound.

Several criteria were used to evaluate the suitability of each fatty acid compound for inclusion in mixture modeling. At a minimum, each compound had to pass GC-MS verification, have a minimal variance for the majority of samples collected $(<20 \%$ relative standard deviation), and average at least $1 \%$ of the total fatty acid contained in each sample. The compounds needed to be predominately from a dietary source, as delineated in Iverson et al. (2004). Compounds 18:2n-6 and 18:3n-3 were automatically included as neither compound is biosynthesized by seals. These selection criteria led to a suite of 22 fatty acid compounds to be used in mixture modeling: C16:2n-6, C16:2n-4, C16:4n-1, C18:1n-9, C18:1n-7, C18:2n-6, C18:3n-6, C18:3n-4, C18:3n-3, C18:4n-3, C20:1n-11, C20:1n-9, C20:1n-7, C20:2n-6, C20:3n-6, C20:4n-6, C20:3n-3, C20:4n-3, C20:5n-3, C22:6n-3, C21:5n-3, and C22:5n-6. Data are available at the Biological and Chemical Oceanography Data Management Office of the National Science Foundation (http://osprey.bcodmo.org/project.cfm?flag=viewr $\& \mathrm{id}=224 \&$ sortby=project).

\section{Estimating diet composition}

Obtaining unique estimates of diet composition with mixture models requires the number of prey classes to be no greater than the number of fatty acids (e.g., Phillips, 2001). Furthermore, combining prey classes reduces the dimensionality of the parameter space and can increase estimation precision. Linear discriminant functions were used to identify prey classes with potential to be merged, with $\mathrm{R}$ software, vers. 2.10.1 ( $\mathrm{R}$ Development Core Team, 2009) and function lda of package MASS (Venables and Ripley, 2002). The accuracy of classifying individual prey into correct prey classes was estimated with discriminant functions and cross validation. Data from each prey specimen were removed temporarily, discriminant functions were estimated from the remaining data, and the estimated functions were used to classify the excluded specimen to a prey class. Prey classes with the largest misclassification rates were candidates to be merged, provided that the mean adipose masses of the 2 classes were similar.

Methods of QFASA mixture modeling closely followed those of Iverson et al. (2004) and Beck et al. (2007), methods that have been applied to the research of numerous marine species, including harbor seals (Nordstrom et al., 2008), gray seals (Halichoerus grypus; Iverson et al., 2004; Beck et al., 2007; Tucker et al., 2008; Lundstrom et al., 2010), harp seals (Pagophilus groenlandicus; Iverson et al., 2004), northern fur seals (Callorhinus ursinus; Hofmeyr et al., 2010), Steller sea lions (Eumetopias jubatus; Hoberecht, 2006), polar bears (Ursus maritimus; Thiemann et al.,
2008), and various species of seabirds (Williams et al., 2009). A mixture model based on the Kullback-Liebler (KL) distance measure (Iverson et al., 2004) was used to estimate the diet composition of each seal. The calibration coefficients for harbor seals reported by Nordstrom et al. (2008) were used to convert prey fatty acid signatures (FAS) to the scale of predator FAS, and the distance measure was evaluated on the predator scale; note that Iverson et al. (2004) converted predator FAS to the prey scale. Estimation variance for each seal was estimated with 1000 bootstrap replications of the prey FAS data. The resulting estimates of diet composition (fat unadjusted, the $p_{k}$ of Iverson et al., 2004), also were transformed to account for adipose mass per prey, expressing diet composition in terms of the number of animals consumed (fat adjusted, the $a_{k}$ of Iverson et al., 2004).

Multivariate analysis of variance (function manova in R; R Development Core Team, 2009) was used to explore diet composition estimates for structure associated with the following covariates: sampling location, season (spring, fall, winter), and sex. The initial model contained these 3 main effects and all 2-way interactions, and nonsignificant terms were sequentially eliminated from the model. A significance level $(\alpha)$ of 0.01 was used for all tests. The mean diet composition for a class of predators (e.g., males or females) was computed as the sample average of their individual diet composition estimates. The variance of mean diet composition was assessed with the estimator of Beck et al. (2007). Mixture proportions and variances were estimated with a custom computer program written in Fortran (Metcalf et al., 2004) and compiled with the Intel Visual Fortran Compiler Professional Edition, vers. 11.1 (Intel Corp., Santa Clara, CA).

\section{Results}

\section{Estimating diet composition}

Given the suite of 22 fatty acid compounds used to form FAS, the 27 original prey classes needed to be reduced to no more than 22 prey classes for mixture model estimates to be unique (Phillips, 2001). Among the 27 original prey types, Black and Yellowtail Rockfish; medium-size Chinook and Coho Salmon; small Chinook, Chum, Sockeye, and Pink Salmon; young Pacific Herring aged 0 to 1 and Pacific Sand Lance; and Kelp Greenling, Pacific Staghorn Sculpin, and Starry Flounder were combined to reduce discriminant analysis misclassification among prey classes (Table 2). The resulting prey data set contained 19 prey classes, for which 251 of 269 prey animals (93.3\%) were assigned to the correct prey class.

The mean diet composition of all 49 seals, both adjusted and unadjusted for differential fat mass among prey, was estimated with FAS for 22 fatty acid compounds and data for 19 prey classes. The species esti- 


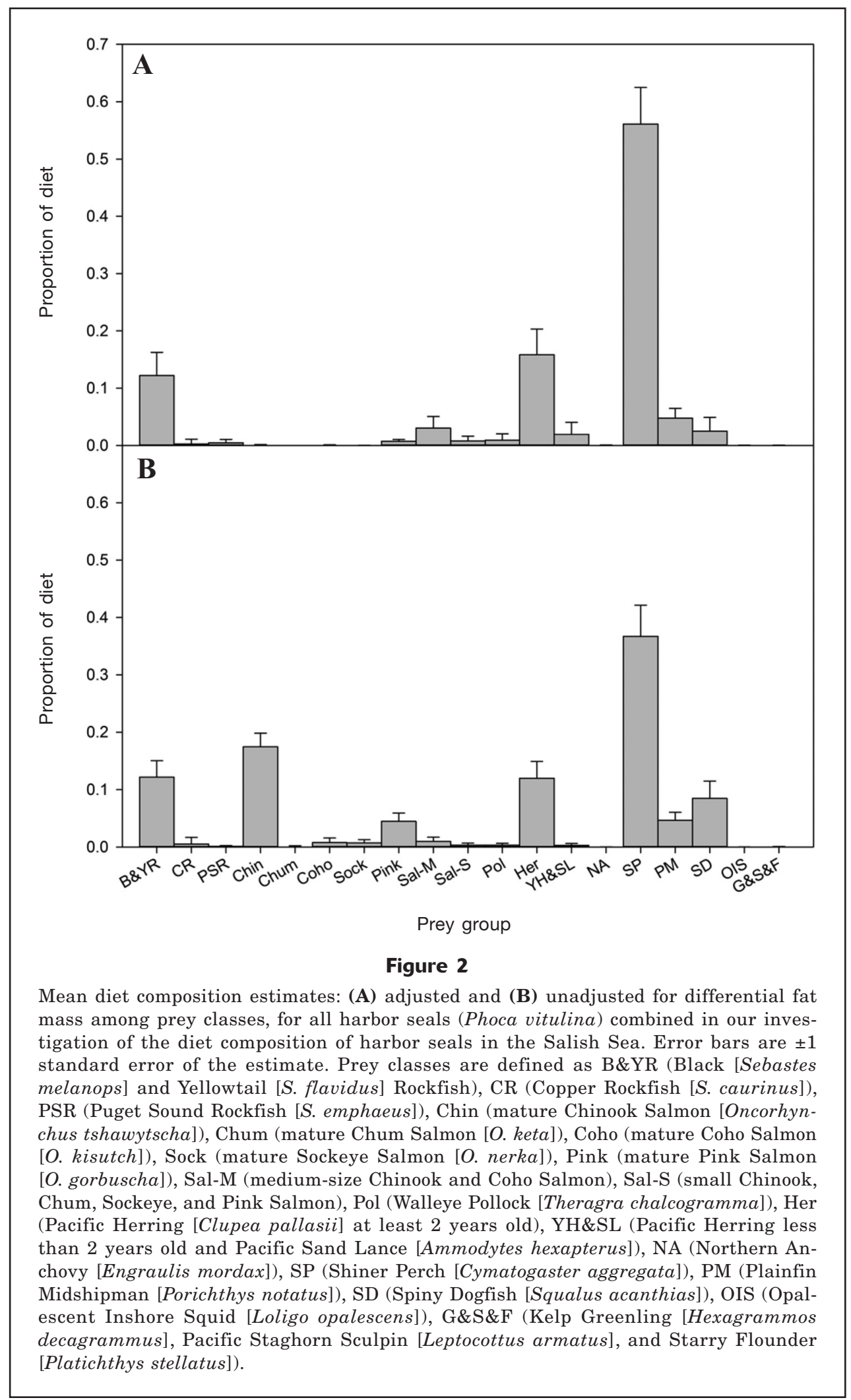


mated to contribute most to harbor seal diets included Black and Yellowtail Rockfish, Chinook Salmon, adult Pacific Herring, and Shiner Perch (Fig. 2). Large differences in fat mass among prey classes led to substantial differences in the 2 estimates. Most noticeably, the high fat content of mature salmon species (Table 2) reduced the contribution of adult Chinook Salmon in the estimates adjusted for fat mass, suggesting that few individual Chinook Salmon need to be consumed for them to contribute significantly to the fat composition of harbor seals.

Multivariate analysis of variance results revealed substantial heterogeneity among estimated diets of individual seals by sampling location $(P<0.001)$ and sex $(P<0.001)$, although the interaction was not statistically significant $(P=0.111)$. For that reason, the 49 seals were independently stratified by sampling location and sex and the mean diet composition, unadjusted for differential fat mass, was estimated for the seals in each stratum. Season was eliminated from the model because it was not a statistically important covariate (see Discussion section). Seals sampled in the vicinity of Belle Chain and Bird Rocks, both of which are characterized by rocky, high-current habitat, had the most diverse diets, with important contributions from Black and Yellowtail Rockfish, adult salmon species, Pacific Herring, Shiner Perch, and Spiny Dogfish (Fig. 3). Conversely, seals sampled from Padilla Bay, which consists of shallow estuarine habitat, had diets that were, on average, dominated by Shiner Perch. Harbor seals sampled near Vendovi Island, which has rocky habitat with nearby access to several bays, appeared to have an intermediate diet.

Male harbor seals were estimated to consume larger quantities of Black and Yellowtail Rockfish, Pacific Herring, and Spiny Dogfish than females, for which Shiner Perch appeared to be more important (Fig. 4). Diet estimates for individual seals reflected additional between-seal heterogeneity that was not explained by the covariates. For example, although
Black and Yellowtail rockfish were estimated to be more important to males than females overall, males were not consistent in their reliance on rockfish species. Of the 24 males sampled, 10 had an estimated

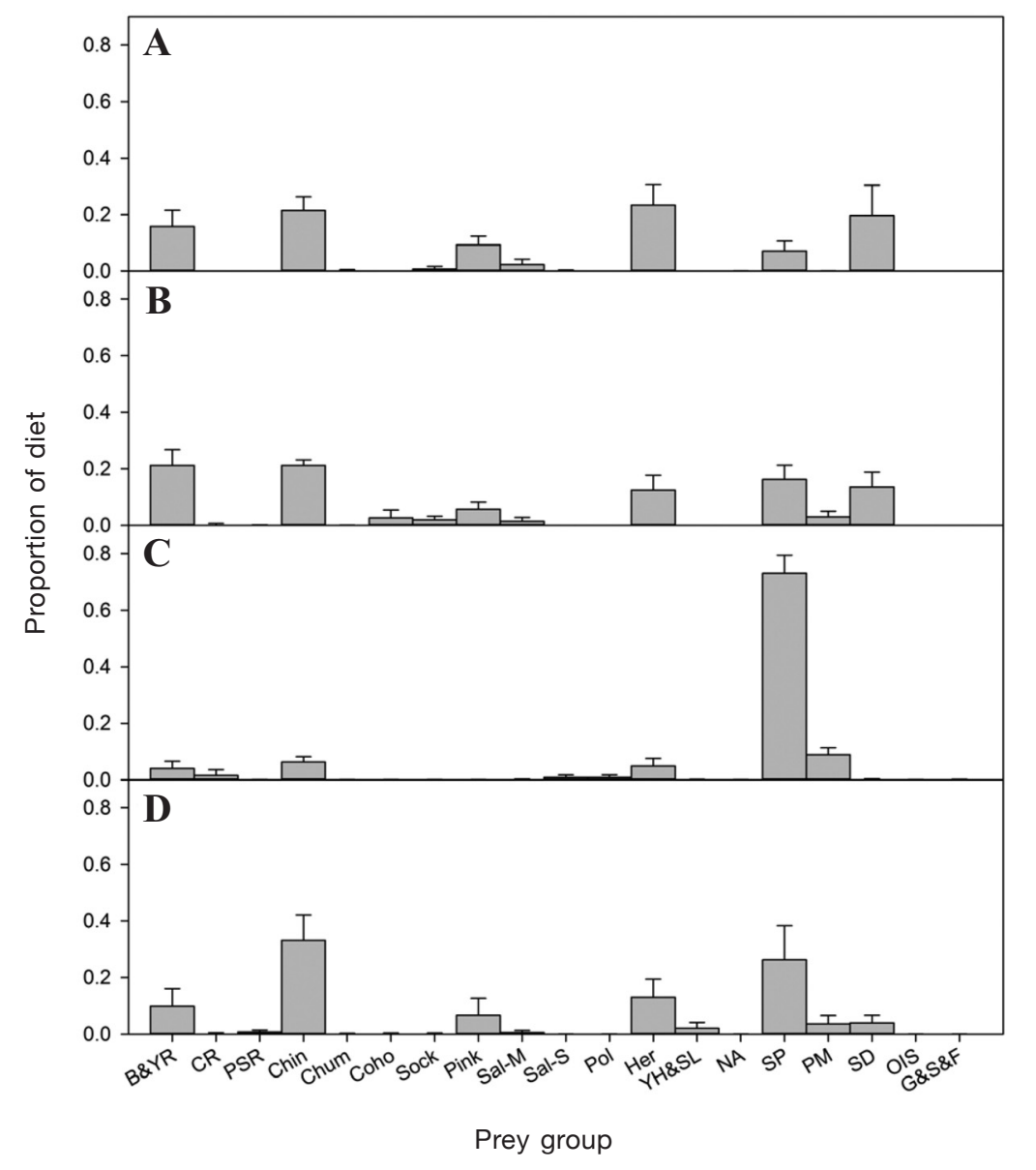

Figure 3

Estimates of mean diet composition for harbor seals (Phoca vitulina) in the Salish Sea, unadjusted for differential fat mass among prey classes, by sampling location: (A) Belle Chain Islets, (B) Bird Rocks, (C) Padilla Bay, and (D) Vendovi Island. Error bars are \pm 1 standard error of the estimate. Prey classes are defined as B\&YR (Black [Sebastes melanops] and Yellowtail [S. flavidus] Rockfish), CR (Copper Rockfish [S. caurinus]), PSR (Puget Sound Rockfish [S. emphaeus]), Chin (mature Chinook Salmon [Oncorhynchus tshawytscha]), Chum (mature Chum Salmon [O. keta]), Coho (mature Coho Salmon [O. kisutch]), Sock (mature Sockeye Salmon [O. nerka]), Pink (mature Pink Salmon [O. gorbuscha]), Sal-M (medium-size Chinook and Coho Salmon), Sal-S (small Chinook, Chum, Sockeye, and Ppink Salmon), Pol (Walleye Pollock [Theragra chalcogramma]), Her (Pacific Herring [Clupea pallasii] at least 2 years old), YH\&SL (Pacific Herring less than 2 years old and Pacific Sand Lance [Ammodytes hexapterus]), NA (Northern Anchovy [Engraulis mordax]), SP (Shiner Perch [Cymatogaster aggregata]), PM (Plainfin Midshipman [Porichthys notatus]), SD (Spiny Dogfish [Squalus acanthias]), OIS (Opalescent Inshore Squid [Loligo opalescens]), G\&S\&F (Kelp Greenling [Hexagrammos decagrammus], Pacific Staghorn Sculpin [Leptocottus armatus], and Starry Flounder [Platichthys stellatus]). 
diet composition of $0.0 \%$ for Black and Yellowtail Rockfish, and estimates for the remaining 14 males ranged from $8.2 \%$ to $51.4 \%$ and averaged $31.8 \%$. Although females were more consistent in their reliance on Shiner

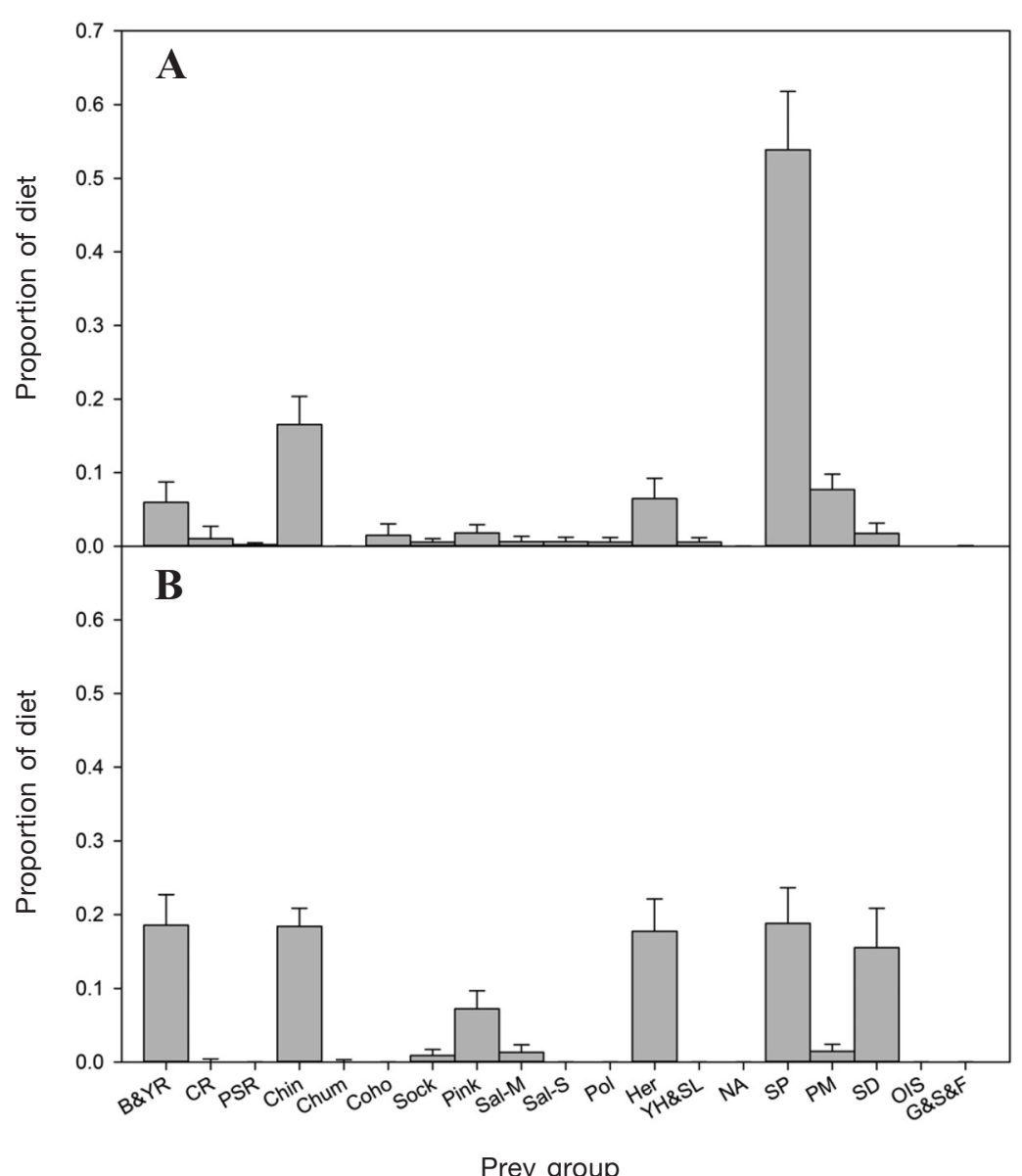

Figure 4

Mean diet composition estimates for harbor seals (Phoca vitulina) in the Salish Sea, unadjusted for differential fat mass among prey classes, by sex: (A) females and (B) males. Error bars are \pm 1 standard error of the estimate. Prey classes are defined as B\&YR (Black [Sebastes melanops] and Yellowtail [S. flavidus] Rockfish), CR (Copper Rockfish [S. caurinus]), PSR (Puget Sound Rockfish [S. emphaeus]), Chin (mature Chinook Salmon [Oncorhynchus tshawytscha]), Chum (mature Chum Salmon [O. keta]), Coho (mature Coho Salmon [O. kisutch]), Sock (mature Sockeye Salmon [O. nerka]), Pink (mature Pink Salmon [O. gorbuscha]), Sal-M (mediumsize Chinook and Coho Salmon), Sal-S (small Chinook, Chum, sockeye, and Pink Salmon), Pol (Walleye Pollock [Theragra chalcogramma]), Her (Pacific Herring [Clupea pallasii] at least 2 years old), YH\&SL (Pacific Herring less than 2 years old and Pacific Sand Lance [Ammodytes hexapterus]), NA (Northern Anchovy [Engraulis mordax]), SP (Shiner Perch [Cymatogaster aggregata]), PM (Plainfin Midshipman [Porichthys notatus]), SD (Spiny Dogfish [Squalus acanthias]), OIS (Opalescent Inshore Squid [Loligo opalescens]), G\&S\&F (Kelp Greenling [Hexagrammos decagrammus], Pacific Staghorn Sculpin [Leptocottus armatus], and Starry Flounder [Platichthys stellatus]).
Perch, the estimated contribution of Black and Yellowwere no discernible patterns in the capture location spect to the magnitude of rockfish estimates for either males or females, a result that is consistent with the nonsignificant interaction between location and gender in the linear model. One female seal was captured twice, at Padilla Bay in spring 2007 and at Vendovi Island in winter 2008. The diet composition of this female was estimated to be $\sim 90 \%$ Shiner Perch and $\sim 9 \%$ Chinook Salmon, with negligible contributions from other prey classes, on both occasions.

\section{Discussion}

Our findings re-affirm the importance of several commercially important fish species to harbor seal diets, particularly salmon species, Pacific Herring, and Shiner Perch, reported by prior investigators (Scheffer and Slipp, 1944; Everitt et al., 1981; Brown and Mate, 1983; Olesiuk, 1993; Zamon, 2001; Orr et al., 2004; Wright et al., 2007; Thomas et al., 2011; Lance et al., 2012). However, our results also reveal that rockfish species contribute more substantially to harbor seal diets than has been recognized previously, exceeding $10 \%$ of the average diet of all harbor seals combined. Given that QFASA estimates are thought to describe diets integrated over a period of weeks to months (Iverson et al., 2004; Budge et al., 2006), estimates of this magnitude may reflect substantial periodic (and, perhaps, sustained) predation on species of rockfish. Although quantitative estimates of rockfish abundance are unavailable, rockfish populations are considered depressed and, given the regional abundance of harbor seals (Jeffries et al., 2003), the predation rates indicated by these findings may be sufficiently high to influence their population dynamics, on a local or, perhaps, regional scale. Consequently, management plans to enhance rockfish abundance may need to give greater consideration to the potential influence of pinniped 
predation. Additional research to verify and refine our estimates of diet composition, and to begin quantifying rockfish population dynamics and the influence of pinniped predation through incorporation of information on harbor seal consumption rates (Howard, 2009; Howard et al., 2013) is warranted.

Although rockfish species appear to constitute a more foundational prey resource for harbor seals than was recognized previously, harbor seal diets do not appear to be homogeneous, a finding that is consistent with the results of observational studies of predatory behavior (Suryan and Harvey, 1998; Tollit et al., 1998; London, 2006; Wright et al., 2007; Hardee, 2008; Thomas et al., 2011; Peterson et al., 2012). Substantial spatial heterogeneity in diet composition was detected among seals from the 4 sampling locations. For example, the mean diet of seals sampled near Padilla Bay was dominated by Shiner Perch, a common species in bays and estuaries throughout the west coast of North America (Hart, 1973). Seals sampled from the other locations, which are characterized by deeper and more open waters and greater rocky relief, tended to rely more on species of rockfish and salmon and $\mathrm{Pa}$ cific Herring. Spatial patterns of habitat suitability undoubtedly underlie the relative abundance of prey in local areas-a dynamic that is subsequently reflected in seal diets. Heterogeneity among sexes also was observed; a more diverse diet and greater use of rockfish species and Spiny Dogfish were observed for male seals than for females. Sex-based heterogeneity in diet was not expected, given the slight sexual dimorphism in harbor seals, but it may reflect a number of factors, including intersexual competition for food resources, foraging behavior, predatory efficiency, and differences in reproductive investment. For example, reproductively active females tend to make shorter foraging trips during early lactation (Boness et al., 1994)-behavior that may reduce their access to some prey classes.

Although the sampling location and sex covariates explained primary patterns among estimates of seal diet composition, substantial unexplained heterogeneity was observed in the estimates. In particular, Black and Yellowtail Rockfish were among the most important prey species for a number of individual seals, especially males, but they were absent from the diets of other seals. Whether differences between individual seals could be explained by unmeasured covariates or are attributable to individual preference or specialization is unknown. In either case, this heterogeneity with respect to rockfish predation is an intriguing aspect of the results of this study.

Our estimates of mean diet composition are not thought to provide an accurate assessment of harbor seal diets on an annual basis. Most seals were sampled in the spring (Table 1), and no seals were sampled from late May through late October. One would expect season to be an important covariate that could explain differences in diets, especially given the large changes in the relative abundance of prey during the spring spawning migration of Pacific Herring and the summer availability of migrating adult salmon species (Stasko et al., 1976; Willson and Womble, 2006; Therriault et al., 2009; Thomas et al., 2011). We surmise that such temporal heterogeneity exists, but that evidence of these seasonally available prey species in harbor seal blubber was diminished by late October. The lack of summer seal samples may partially explain the difference between these results and assessments of harbor seal diet based on scats, in which salmon species and Pacific Herring are prevalent (Luxa, 2008; Lance et al., 2012). A complete assessment of seasonal variation in harbor seal diets would require a somewhat expanded investigation, in which the distribution of sampling effort would be designed to investigate potential changes in diet expected on the basis of seasonally predictable shifts in the availability of prey species. The expected deposition and turnover rates of fatty acid compounds in adipose tissue (Nordstrom et al., 2008) also would contribute importantly to an optimized sample design. On the basis of the results of this investigation, an expanded effort to more fully explore spatial, temporal, and demographic patterns in harbor seal diets likely would be successful.

Two estimates of mean diet composition, one unadjusted and one adjusted for differential fat mass of prey, were provided for all seals combined (Fig. 2). However, no adjustment for differential fat mass was made for the estimates stratified by location and sex. The large differences in fat composition among the prey classes (Table 2) and, to a lesser extent, the lack of total mass data for mature Chinook, Sockeye, and Pink Salmon, all of which have high fat content, somewhat reduce our confidence in the fat-adjusted estimates. The estimates unadjusted for differential fat mass are informative ecologically, providing information on the likely sources of adipose tissue ingested by harbor seals. Fatadjusted estimates may be of greater interest from the perspective of prey population demographics because rescaling the estimates with mean fat per prey converts the units to the relative numbers (proportions) of prey animals consumed. Given an estimate of the number of fish consumed per unit of time, the fat-adjusted estimates would facilitate the investigation of predation rates by prey class.

Although QFASA is a powerful method for investigation of predator diets, it is important to recognize potential problems with its use. With respect to marine mammals, logistical constraints and permit requirements may limit sample sizes and preclude comprehensive investigations of free-ranging populations. From a statistical perspective, it is important to acknowledge that estimates of diet composition are conditioned on the calibration coefficients, the suitability of which in any particular application cannot be verified. In the instance of this investigation, the calibration coefficients were estimated during a controlled feeding study of captive harbor seals (Nordstrom et al., 2008), the species of interest. Even so, the degree to which the coef- 
ficients are applicable to wild seals with a more diverse diet is unknown, and use of previously published coefficients is a potential source of bias. To conduct an independent feeding trial in association with every field investigation obviously is infeasible and therefore reliance on published calibration coefficients may be unavoidable. However, some investigators have noted that diet composition estimates are sensitive to the values of calibration coefficients (Meynier et al., 2010), and such sensitivity may also be the case for the suite of fatty acid compounds used in mixture modeling. Achievement of adequate sample sizes of all potential prey species, including representatives of the same species at various life history stages and seasons, such as immature and mature species of salmon, is obviously an important precursor to implementation of QFASA. Although such considerations do not negate the utility of QFASA as a tool to estimate diet composition, researchers need to be cognizant of these issues, and therefore the development of analytical procedures to assess sensitivity may be helpful.

\section{Conclusions}

Several fish stocks of historic commercial importance within the Salish Sea are considered to be depressed and their recovery is a high management priority. Whether abundant pinniped populations may be impeding management actions intended to stimulate recovery is an open question in this region. Our findings confirmed the importance of salmon species and Pacific Herring in harbor seal diets, but they also revealed that other species, including rockfish species, may contribute more substantially to harbor seal diets than had been realized previously. Although estimates of harbor seal diet composition varied spatially, demographically, and among individual seals, species of rockfish were estimated to compose a large proportion of the diets of several individual seals. These results, in combination with the current high abundance of harbor seals, indicate that predation may be an important ecological factor in the regulation of the local and regional abundance of rockfish populations-a possibility that warrants additional investigation.

\section{Acknowledgments}

We thank B. Applegate, R. Tee, and S. Ali for their assistance in the ASET Laboratory; B. Hagedorn for logistical support and direction; D. Lambourn, B. Murphie, J. Gould, T. Cyra, J. Gaydos, K. Reuland, S. Peterson, P. Olesiuk, and many others for their help capturing seals; R. Sweeting (Fisheries and Oceans Canada and RV Ricker), S. O'Neill (NOAA), and G. Williams (NOAA) for providing fish samples; A. Default (NOAA), and Western Washington University students for assistance processing fish samples; and A. Thomas for creat- ing Figure 1. We also thank K. Oakley (U.S. Geological Survey) for providing helpful comments that greatly improved the manuscript. This study was supported by National Science Foundation Award No. 0550443 to A. Acevedo-Gutiérrez, the University of Alaska Anchorage, Washington Department of Fish \& Wildlife, Olympia, Washington, U. S. Geological Survey, and the Alaska Science Center. Harbor seal research activities were conducted under Marine Mammal Protection Act Research Permit 782-1702-00.

\section{Literature cited}

Ackman, R. G.

1989. Marine biogenic lipids, fats, and oils, vol. 2, 472 p. CRC Press, Inc., Boca Raton, FL.

Beck, C. A., S. J. Iverson, W. D. Bowen, and W. Blanchard.

2007. Sex differences in grey seal diet reflect seasonal variation in foraging behaviour and reproductive expenditure: evidence from quantitative fatty acid signature analysis. J. Anim. Ecol. 76:490-502.

Bjørge, A., T. Bekkby, V. Bakkestuen, and E. Framstad.

2002. Interaction between harbour seals, Phoca vitulina, and fisheries in complex coastal waters explored by combined geographic information system (GIS) and energetics modelling. ICES J. Mar. Sci. 59:29-42.

Boness, D. J., W. D. Bowen, and O. T. Oftedal.

1994. Evidence of a maternal foraging cycle resembling that of otariid seals in a small phocid, the harbor seal. Behav. Ecol. Sociobiol. 34:95-104.

Bowen, W. D., J. W. Lawson, and B. Beck.

1993. Seasonal and geographic variation in the species composition and size of prey consumed by grey seals (Halichoerus grypus) on the Scotian Shelf. Can. J. Fish. Aquat. Sci. 50:1768-1778.

Boyd, I. L.

2002. Estimating food consumption of marine predators: Antarctic fur seals and macaroni penguins. J. Appl. Ecol. 39:103-119.

Brown, R. F., and B. R. Mate.

1983. Abundance, movements, and feeding habits of harbor seals, Phoca vitulina, at Netarts and Tillamook Bays, Oregon. Fish. Bull. 81:291-301.

Browne, P., J. L. Laake, and R. L. DeLong.

2002. Improving pinniped diet analyses through identification of multiple skeletal structures in fecal samples. Fish. Bull. 100:423-433.

Budge, S. M., S. J. Iverson, W. D. Bowen, and R. G. Ackman. 2002. Among- and within-species variability in fatty acid signatures of marine fish and invertebrates on the Scotian Shelf, Georges Bank, and southern Gulf of St. Lawrence. Can. J. Fish. Aquat. Sci. 59:886-898.

Budge, S. M., S. J. Iverson, and H. N. Koopman.

2006. Studying trophic ecology in marine ecosystems using fatty acids: a primer on analysis and interpretation. Mar. Mamm. Sci. 22:759-801.

Cottrell, P. E., and A. W. Trites.

2002. Classifying prey hard part structures recovered from fecal remains of captive Steller sea lions (Eumetopias jubatus). Mar. Mamm. Sci. 18:525-539. 
Dodds, E. D., M. R. McCoy, A. Geldenhuys, L. D. Rea, and J. M. Kennish.

2005. Microscale recovery of total lipids from fish tissue by accelerated solvent extraction. J. Am. Oil Chem. Soc. 81:835-840.

Everitt, R. D., P. J. Gearin, J. S. Skidmore, and R. L. DeLong. 1981. Prey items of harbor seals and California sea lions in Puget Sound. Murrelet 62:83-86.

Federal Register.

2007. Endangered and threatened species: final listing determination for Puget Sound steelhead, vol. 72, no. 91, May 11, p. 26722-26735. GPO, Washington, D.C.

2010. Endangered and threatened wildlife and plants: threatened status for the Puget Sound/Georgia Basin distinct population segments of yelloweye and canary rockfish and endangered status for the Puget Sound/ Georgia Basin distinct population segment of bocaccio rockfish, vol. 75, no. 81, April 28, p. 22276-22290. GPO, Washington, D.C

Fu, C., R. Mohn, and L. P. Fanning.

2001. Why the Atlantic cod (Gadus morhua) stock off eastern Nova Scotia has not recovered. Can. J. Fish. Aquat. Sci. 58:1613-1623.

Hardee, S. E.

2008. Movements and home ranges of harbor seals $(P h$ oca vitulina) in the inland waters of the Pacific Northwest. M.S. thesis, 148 p. Western Washington Univ., Bellingham, WA.

Hart, J. L.

1973. Pacific fishes of Canada. Fish. Res. Board Can. Bull. 180, 740 p.

Harvey, J. T.

1989. Assessment errors associated with harbour seal (Phoca vitulina) faecal sampling. J. Zool. 219:101-111.

Harwood, J., and J. P. Croxall.

1988. The assessment of competition between seals and commercial fisheries in the North Sea and the Antarctic. Mar. Mamm. Sci. 4:13-33.

Hauser, D. D. W., C. S. Allen, H. B. Rich Jr., and T. P. Quinn. 2008. Resident harbor deals (Phoca vitulina) in Iliamna Lake, Alaska: Summer diet and partial consumption of adult sockeye salmon (Oncorhynchus nerka). Aquat. Mamm. 34:303-309.

Heithaus, M. R., A. Frid, A. J. Wirsing, and B. Worm. 2008. Predicting ecological consequences of marine top predator declines. Trends Ecol. Evol. 23:202-210.

Hoberecht, L. K.

2006. Investigating the use of blubber fatty acids to detect Steller sea lion (Eumetopias jubatus) foraging on ephemeral high-quality prey. Ph.D. diss., 247 p. Univ. Washington, Seattle, WA.

Hofmeyr, G., M. Bester, S. Kirkman, C. Lydersen, and K. Kovacs.

2010. Intraspecific differences in the diet of Antarctic fur seals at Nyrøysa, Bouvetøya. Polar Biol. 33:1171-1178.

Holling, C. S.

1959. The components of predation as revealed by a study of small-mammal predation of the European pine sawfly. Can. Entomol. 91:293-320.

Howard, S. M. S.

2009. Energetic requirements and prey consumption of harbor seals (Phoca vitulina) in the San Juan Islands, WA. M.S. thesis, 106 p. Western Washington Univ., Bellingham, WA.
Howard, S. M. S., M. M. Lance, S. J. Jeffries, and A. Acevedo-Gutiérrez

2013. Fish consumption by harbor seals (Phoca vituli$n a)$ in the San Juan Islands, Washington. Fish. Bull. 111:27-41.

Iverson, S. J., C. Field, W. D. Bowen, and W. Blanchard.

2004. Quantitative fatty acid signature analysis: a new method of estimating predator diets. Ecol. Monogr. 74:211-235.

Iverson, S. J., K. J. Frost, and L. F. Lowry.

1997. Fatty acid signatures reveal fine scale structure of foraging distribution of harbor seals and their prey in Prince William Sound, Alaska. Mar. Ecol. Prog. Ser. 151:255-271.

Jeffries, S. J., R. F. Brown, and J. T. Harvey.

1993. Techniques for capturing, handling and marking harbor seals. Aquat. Mamm. 19:21-25.

Jeffries, S. J., H. R. Huber, J. Calambokidis, and J. Laake 2003. Trends and status of harbor seals in Washington State: 1978-1999. J. Wildl. Manage. 67:207-218.

Klare, U., J. F. Kamler, and D. W. Macdonald.

2011. A comparison and critique of different scat-analysis methods for determining carnivore diet. Mamm. Rev. 41:294-312.

Lance, M. M., W. Chang, S. J. Jeffries, S. F. Pearson, and A. Acevedo-Gutiérrez.

2012. Harbor seal diet in northern Puget Sound: implications for the recovery of depressed fish stocks. Mar. Ecol. Prog. Ser. 464:257-271.

Levin, P. S., E. E. Holmes, K. R. Piner, and C. J. Harvey. 2006. Shifts in a Pacific Ocean fish assemblage: the potential influence of exploitation. Conserv. Biol. 20:1181-1190.

London, J. L.

2006. Harbor seals in Hood Canal: predators and prey. Ph.D. diss., 90 p. Univ. Washington, Seattle, WA.

Lundstrom, K., O. Hjerne, S. Lunneryd, and O. Karlsson.

2010. Understanding the diet composition of marine mammals: Grey seals (Halichoerus grypus) in the Baltic Sea. ICES J. Mar. Sci. 67:1230-1239.

Luxa, $\mathrm{K}$

2008. Food habits of harbor seals (Phoca vitulina) in two estuaries in northern Puget Sound,Washington. M.S. thesis, 87 p. Western Washington Univ., Bellingham, WA.

MacKenzie, B. R., E. Margit, and H. Ojaveer.

2011. Could seals prevent cod recovery in the Baltic Sea? PLoS ONE 6:e18988.

Metcalf, M., J. Reid, and M. Cohen.

2004. Fortran 95/2003 explained, 416 p. Oxford Univ. Press, New York.

Meynier, L., P. Morel, B. Chilvers, D. Mackenzie, and P. Duignan.

2010. Quantitative fatty acid signature analysis on New Zealand sea lions: model sensitivity and diet estimates. J. Mammal. 91:1484-1495.

Middlemas, S. J., T. R. Barton, J. D. Armstrong, and P. M. Thompson.

2006. Functional and aggregative responses of harbour seals to changes in salmonid abundance. Proc. R. Soc. Lond., Ser. B: Biol. Sci. 273:193-198.

Musick, J. A., M. M. Harbin, S. A. Berkeley, G. H. Burgess, A. M. Eklund, L. Findley, R. G. Gilmore, J. T. Golden, D. S. Ha, G. R. Huntsman, J. C. McGovern, S. J. Parker, S. G. Poss, 
E. Sala, T. W. Schmidt, G. R. Sedberry, H. Weeks, and S. G. Wright.

2001. Marine, estuarine, and diadromous fish stocks at risk of extinction in North America (exclusive of Pacific salmonids). Fisheries 25:6-30.

Nordstrom, C. A., L. J. Wilson, S. J. Iverson, and D. J. Tollit.

2008 Evaluating quantitative fatty acid signature analysis (QFASA) using harbour seals Phoca vitulina richardsi in captive feeding studies. Mar. Ecol. Prog. Ser. 360:245-263.

Olesiuk, P. F.

1993. Annual prey consumption by harbor seals ( $P h$ oca vitulina) in the Strait of Georgia, British Columbia. Fish. Bull. 91:491-515.

Orr, A. J., A. S. Banks, S. Mellman, H. R. Huber, R. L. DeLong, and R. F. Brown.

2004. Examination of the foraging habits of Pacific harbor seal (Phoca vitulina richardsi) to describe their use of the Umpqua River, Oregon, and their predation on salmonids. Fish. Bull. 102:108-117.

Peterson, S. H., M. M. Lance, S. J. Jeffries, and A. Acevedo-Gutiérrez.

2012. Long distance movements and disjunct spatial use of harbor seals (Phoca vitulina) in the inland waters of the Pacific Northwest. PLoS ONE 7(6):e39046. doi:10.1371/journal.pone.0039046

Phillips, D. L.

2001. Mixing models in analyses of diet using multiple stable isotopes: A critique. Oecologia 127:166-170.

Phillips, E. M., and J. T. Harvey.

2009. A captive feeding study with the Pacific harbor seal (Phoca vitulina richardsii): Implications for scat analysis. Mar. Mamm. Sci. 25:373-391.

Quinn, T. P.

2005. The behavior and ecology of Pacific salmon and trout. Univ. Washington Press, Seattle, WA.

$\mathrm{R}$ Development Core Team.

2009. R: A language and environment for statistical computing. R Foundation for Statistical Computing, Vienna, Austria. [Available from http://www.R-project.org/, accessed August 2011.]

Roper, C. F. E., M. J. Sweeney, and C. E. Nauen.

1984. FAO species catalogue. Vol. 3. Cephalopods of the world: an annotated and illustrated catalogue of species of interest to fisheries. FAO Fish. Synop. 125, vol. 3, $277 \mathrm{p}$.

Scheffer, V. B., and J. W. Slipp.

1944. The harbor seal in Washington State. Am. Midl. Nat. 32:373-416.

Schmitz, O. J., D. Hawlena, and G. C. Trussell.

2010. Predator control of ecosystem nutrient dynamics. Ecol. Lett. 13:1199-1209.

Sergio, F., I. Newton, L. Marchesi, and P. Pedrini.

2006. Ecologically justified charisma: Preservation of top predators delivers biodiversity conservation. J. Appl. Ecol. 43:1049-1055.

Stasko, A.B., R. M. Horrel, and A. D. Hasler.

1976. Coastal movements of adult Fraser River salmon (Oncorhynchus nerka) observed by ultrasonic tracking. Trans. Am. Fish. Soc. 105:64-74.

Suryan, R. M., and J. T. Harvey.

1998. Tracking harbor seals (Phoca vitulina richardsi) to determine dive behavior, foraging activity, and haul-out site use. Mar. Mamm. Sci. 14:361-372.
Therriault, T.W., D. E. Hay, and J. F. Schweigert.

2009. Biological overview and trends in pelagic forage fish abundance in the Salish Sea (Strait of Georgia, British Columbia). Mar. Ornithol. 37: 3-8.

Thiemann, G. W., S. J. Iverson, and I. Stirling.

2008. Polar bear diets and arctic marine food webs: insights from fatty acid analysis. Ecol. Monogr. 78:591-613.

Thomas, A. C., M. M. Lance, S. J. Jeffries, B. G. Miner, and A. Acevedo-Gutiérrez.

2011. Harbor seal foraging response to a seasonal resource pulse, spawning Pacific herring. Mar. Ecol. Prog. Ser. 441:225-239.

Tollit, D. J., A. D. Black, P. M. Thompson, A. Mackay, H. M. Corpe, B. Wilson, S. M. Van Parijs, K. Grellier, and S. Parlane.

1998. Variations in harbour seal (Phoca vitulina) diet and dive-depths in relation to foraging habitat. J. Zool. 244:209-222.

Tollit, D. J., S. G. Heaslip, R. Joy, K. A. Call, and A. W. Trites. 2004. A method to improve size estimates of Walleye pollock (Theragra chalcogramma) and Atka mackerel (Pleurogrammus monopterygius) consumed by pinnipeds: digestion correction factors applied to bones and otoliths recovered in scats. Fish. Bull. 102:498-508.

Tollit, D. J., M. J. Steward, P. M. Thompson, G. J. Pierce, M. B. Santos, and S. Hughes.

1997. Species and size differences in the digestion of otoliths and beaks: implications for estimates of pinniped diet composition. Can. J. Fish. Aquat. Sci. 54:105-119.

Trites, A. W., and R. Joy.

2005. Dietary analysis from fecal samples: How many scats are enough? J. Mammal. 86:704-712.

Tucker, S., W. D. Bowen, and S. J. Iverson.

2008. Convergence of diet estimates derived from fatty acids and stable isotopes within individual grey seals. Mar. Ecol. Prog. Ser. 354:267-276.

Venables, W. N., and B. D. Ripley.

2002. Modern applied statistics with S, $4^{\text {th }}$ ed., 512 p. Springer, New York.

Walton, M. J., R. J. Henderson, and P. P. Pomeroy.

2000. Use of blubber fatty acid profiles to distinguish dietary differences between grey seals Halichoerus grypus from two UK breeding colonies. Mar. Ecol. Prog. Ser. 193:201-208.

Walton, M., and P. Pomeroy.

2003. Use of blubber fatty acid profiles to detect interannual variations in the diet of gray seals Halichoerus grypus. Mar. Ecol. Prog. Ser. 248:257-266.

Williams, C. T., S. J. Iverson, and C. L. Buck.

2009. The effects of diet and caloric restriction on adipose tissue fatty acid signatures of tufted puffin (Fratercula cirrhata) nestlings. J. Comp. Physiol., B 179:711-720.

Williams, T. M., J. A. Estes, D. F. Doak, and A. M. Springer. 2004. Killer appetites: Assessing the role of predators in ecological communities. Ecology 85:3373-3384.

Williams, G. D., P. S. Levin, and W. A. Palsson.

2010. Rockfish in Puget Sound: an ecological history of exploitation. Marine Policy 34:1010-1020.

Willson, M. F., and J. N. Womble.

2006. Vertebrate exploitation of pulsed marine prey: a review and the example of spawning herring. Rev. Fish Biol. Fish. 16:183-200. 
Wright, B. E., S. D. Riemer, R. F. Brown, A. M. Ougzin, and K. A. Bucklin.

2007. Assessment of harbor seal predation on adult salmonids in a Pacific Northwest estuary. Ecol. Appl. 17:338-351.
Zamon, J. E.

2001. Seal predation on salmon and forage schools as a function of tidal currents in the San Juan Islands, Washington, USA. Fish. Oceanogr. 10:353366. 